Article

\title{
Incorporation of Corrosion Effects into the Life-Cycle Analysis of AW-2017A-T4 Aluminium Alloy under Bending Moment
}

\author{
Lukasz Blacha ${ }^{1}$, Joanna Małecka ${ }^{2} \mathbb{D}$ and Tadeusz Lagoda ${ }^{1, * \mathbb{D}}$ \\ 1 Department of Mechanics and Machine Design, Opole University of Technology, ul. Mikołajczyka 5, \\ 45-271 Opole, Poland; 1.blacha@po.edu.pl \\ 2 Department of Materials Engineering, Opole University of Technology, ul. Mikołajczyka 5, \\ 45-271 Opole, Poland; j.malecka@po.edu.pl \\ * Correspondence: t.lagoda@po.edu.pl
}

Received: 30 June 2020; Accepted: 18 August 2020; Published: 20 August 2020

\begin{abstract}
The paper presents the results of fatigue tests of corroded AW-2017A-T4 aluminium alloy samples subjected to an alternating (symmetrical) bending load. Although there are a number of works describing pre-corrosion fatigue in aluminium alloys, relatively few of them concern bending fatigue effects, in some selected alloys only. Here, the AW-2017A-T4 samples were exposed to electrochemical preliminary corrosion by immersion in an electrolyte, a 3.5\% solution of $\mathrm{NaCl}$ in water. Several variants of series of samples differing in immersion time were tested. Based on the analysis of the results obtained, Basquin's fatigue characteristics were developed and compared to the characteristics of the material in its nominal state, which allowed for conclusions on the influence of corrosion effects. The characteristic curves show the susceptibility of the test material to corrosive processes, which results in a decrease in fatigue life along with the increase of pre-corrosion time. The samples with longer immersion duration revealed larger surface losses and widespread corrosion pits.
\end{abstract}

Keywords: AW-2017A-T4 aluminium alloy; pre-corrosion; bending fatigue

\section{Introduction}

Structures made of aluminium alloys are widely applied in the construction industry [1-3], the aerospace and aviation industry $[4,5]$, the automotive industry $[6,7]$ and military applications [8]. The popularity of this material is mainly due to its relatively low density, good strength-to-mass ratio, high corrosion resistance, and good ability to be welded, including with other materials [9-11]. These properties make it possible to reduce operating costs: low weight means low energy consumption. In the same way, maintenance costs can also be reduced: corrosion resistance higher than that of ferrous metals allows to plan less maintenance effort. The AW-2017A-T4 alloy is used in the construction of machines and structures as a material for construction elements of aircrafts, vehicles, and military equipment [12,13].

Corrosion processes are the cause of degradation of the material. They arise as a result of the destruction processes and lead to a decrease in strength and operational parameters (i.e., fatigue life). The initiation of such a process has its origin in the chemical or electrochemical environmental impact. In electrochemical corrosion, a typical structure damage is initiated by a corrosion pit, small hole created in a process of localised corrosion. The formation of possible corrosion pits in the material will result in a loss of strength due to a source of stress concentration. Electrochemical corrosion occurs in a corrosive environment, such as an electrolyte. In such an environment, local depassivation occurs on a small area of the metal which becomes an anode while the nearby area behaves as a cathode. 
An example of an electrolyte is a solution of water with a dissolved substance accelerating corrosion. Increased resistance of aluminium alloys to electrochemical corrosion is due to the phenomenon of passivation, i.e., the formation of a passive layer on the external surface of the material, which prevents the formation of corrosive cells. The retention of such a state depends on the electrode potential. Therefore, the comparative analysis of operational parameters in atmospheric conditions and after a period of functioning in a corrosive environment (in an electrolytic conductor) is important to analyze. One of the operational parameters is fatigue life, which is characterized by resistance to the accumulation of damage in the material caused by the cyclic load.

There are a number of works concerning the development of fatigue cracks in various aluminium alloys subjected to corrosion [14-16], but they usually concern one particular type of environment with strictly defined physicochemical parameters, and the analysed parameter is only the crack development rate, without direct reference to fatigue life. There is also a large number of works describing experimental fatigue strength, but mainly in tension or compression conditions [17-21]. Relatively few of them concern bending or multiaxial conditions, and these are mainly in specialised applications. (e.g., [22]). The knowledge on material resistance to bending fatigue is important in understanding the principles of the effect of corrosion on fatigue properties [23,24]. It becomes especially important in the case of long-span and truss structures [25], axles and shafts [26], airframes [27].

The aim of this work was to explore experimentally life assessment aspects of bending fatigue in the structure-fluid interaction between an aluminium structure and corrosive fluid. The material tested was aluminium alloy AW-2017A-T4 after various periods of exposure to $3.5 \mathrm{wt} \% \mathrm{NaCl}$ solution in water, i.e., conditions favourable to electrochemical corrosion recognised by the ASTM D1141-98. The obtained data will therefore provide information about the scale of material degradation within a wide range of load history and would be useful in modelling the load-life interaction and the corresponding mechanisms of degradation due to bending fatigue, as the current state of the art still lacks information concerning this topic.

\section{Experimental Research}

The purpose of the tests was to determine the fatigue life in alternating bending conditions. The characteristics of the material tested are presented further in the article.

\subsection{Material and Samples}

The samples were made of the AW-2017A aluminium alloy in a T4 state. Due to the presence of copper in the chemical composition, among other alloys it is classified as difficult to weld and moderately corrosion-resistant $[28,29]$. The chemical composition and static strength properties of the material are presented in Figure 1 and Table 1, respectively. The material was delivered in the form of a bar. The samples had the geometry of a diabolo specimen (Figure 2). They were cut by saw and then manufactured in the processes of turning and milling. Surface roughness $R a$ before the corrosion was 1.25 .

The samples were subjected to corrosion over several days and then used for fatigue testing. The examination of the decohesion surface of the material tested and the evaluation of corrosion damage were carried out with the use of scanning microscope JEOL JSM-840. Secondary electron detection (SE) and backscattered electron detection (BSE) were used to obtain fracture images.

Table 1. Selected strength properties of the test material according to EN 485-2+A1:2018-12 standard.

\begin{tabular}{cccc}
\hline UTS & $Y S_{2 \%}$ & $\begin{array}{c}\mathrm{A} \\
\min , \%\end{array}$ \\
\hline 350 & & 260 & 13 \\
\hline
\end{tabular}




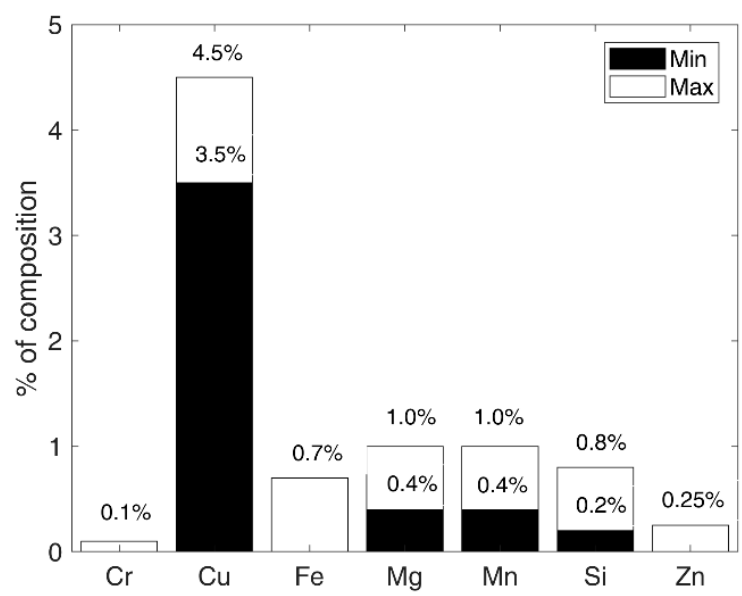

Figure 1. Chemical composition of the test material according to EN 573-3 standard.

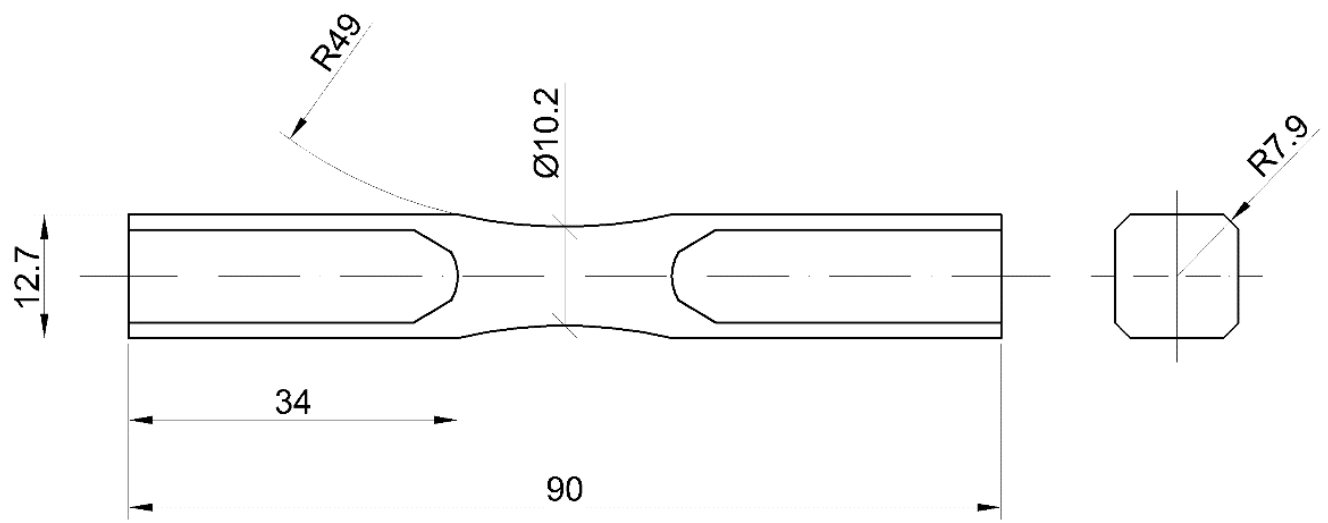

Figure 2. Geometry of samples used for fatigue testing (mm).

\subsection{Corrosion Process}

The corrosion process of the samples was initiated by immersion in an electrolyte, a $3.5 \mathrm{wt} \% \mathrm{NaCl}$ solution in water, for 7, 14 or 28 days (depending on the test series). A $3.5 \%$ salinity was chosen as a reproducible solution for tests on corrosion, recognised by the ASTM D1141-98 standard for the preparation of saline water. The tests were conducted on two series of samples prepared in this way. Samples from the first series were immersed in a solution in tap water; samples from the second series were immersed in a solution in demineralised water. Both series were prepared in several variants differing in the time of immersion in the electrolyte, lasting 7 or 14 days, with an additional variant of 28 days in the case of series in which demineralised water was the solvent (Table 2). Such long immersion periods were chosen in order to fully test the influence of pre-corrosion time on fatigue life, since many tests are accelerated tests (such as salt spray).

Table 2. Test series.

\begin{tabular}{ccc}
\hline Sample Series & Electrolyte & Immersion Duration \\
\hline First series & $3.5 \mathrm{wt} \% \mathrm{NaCl}$ solution in tap water & 7 and 14 days \\
\hline Second series & $3.5 \mathrm{wt} \% \mathrm{NaCl}$ solution in demineralised water & 7,14 and 28 days \\
\hline
\end{tabular}

The samples of a given series were immersed at the same time and in the same container from which all samples of the variant were removed after an appropriate period of time (i.e., after 7, 14 or 28 days, depending on the variant), then washed with demineralised water, and dried. 
The controlled corrosion process took place at room temperature. Its dynamics were determined as dependent on temperature and the properties of the electrolyte, together with the chemical composition of the water. The chemical composition of the water, considered in preparation of the solution used for the preparation of the first series of samples, was assessed using a water quality strip tester (Table 3 ).

Table 3. Chemical composition of water considered in preparing the first series of samples.

\begin{tabular}{cccc}
\hline Fe & Cl & Nitrates & Nitrites \\
\hline \multicolumn{3}{c}{$P p m$} \\
\hline 0.1 & 0.1 & 25.0 & 1.0 \\
\hline
\end{tabular}

The results obtained also made it possible to test the concentration of hydrogen ions, which were determined to be 6.0 on the $\mathrm{pH}$ scale, and to have a hardness of $180 \mathrm{ppm}$.

\subsection{Fatigue Tests}

The tests were carried out at the monitored bending moment at a frequency of $28.8 \mathrm{~Hz}$. The samples were subjected to constant-amplitude bending loads where asymmetry coefficient $R=-1$. All tests were carried out on the MZGS-100 test stand [30] made at the Opole University of Technology, which enables fatigue testing in combined conditions of bending and torsion load (Figure 3).

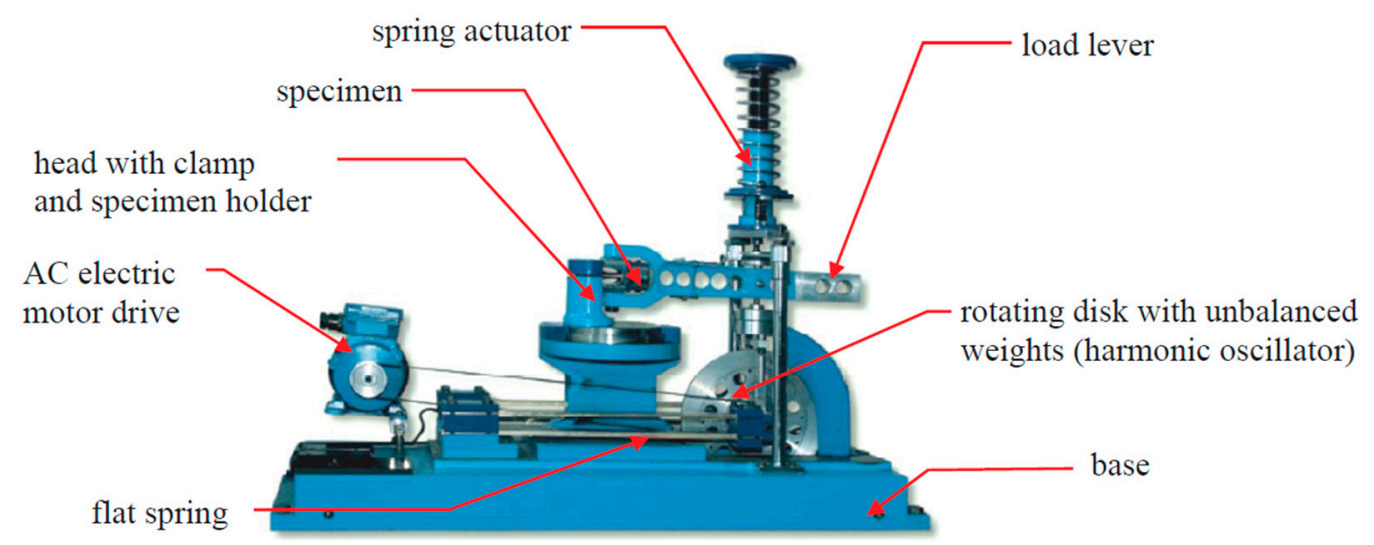

Figure 3. The overall view of the MZGS-100 test stand [30].

The load was applied on the test bench by setting the clamping lever on one side of the sample in a vibrating motion. The load combination was realized by an appropriate angular offset of the column holding the other side of the sample. The tests were carried out with zero offset.

The failure criterion was assumed to be a $15 \%$ decrease in bending moment, appearing always at the very end of test. The corresponding number of cycles was assumed as the durability, $N_{f}$. The stress on the sample surface was determined according to the linear-elastic body model under the assumption of flat bending (Equation (1)).

\section{Results}

The results of fatigue tests are shown in Tables $4-8$, where $M_{b, a}$ is bending moment amplitude, and $\sigma_{a}$ is stress amplitude, calculated as follows:

$$
\sigma_{a}=\frac{M_{b, a}}{W}=\frac{32 M_{b, a}}{\pi d^{3}}
$$

where $W=$ the bending resistance moment about the neutral axis, $d=$ the diameter of the sample on the test section-here, $10.2 \mathrm{~mm}$. 
Table 4. Results of fatigue tests of samples after 7 days of immersion in a $3.5 \% \mathrm{NaCl}$ solution in tap water.

\begin{tabular}{cccc}
\hline \multirow{2}{*}{ No. } & $\boldsymbol{M}_{\boldsymbol{b}, \boldsymbol{a}}$ & $\sigma_{\boldsymbol{a}}$ & $\boldsymbol{N}_{\boldsymbol{f}}$ \\
\cline { 2 - 4 } & $\mathbf{N m}$ & $\mathbf{M P a}$ & - \\
\hline 1 & 16.4 & 162.14 & 297,798 \\
2 & 16.6 & 164.11 & 271,494 \\
3 & 16.4 & 162.14 & 125,644 \\
4 & 11.0 & 108.75 & 852,785 \\
5 & 10.6 & 104.79 & 964,988 \\
6 & 10.8 & 106.77 & 485,289 \\
7 & 10.9 & 107.76 & 605,299 \\
8 & 10.5 & 103.81 & $1,208,290$ \\
\hline
\end{tabular}

Table 5. Results of fatigue tests of samples after 14 days of immersion in a $3.5 \% \mathrm{NaCl}$ solution in tap water.

\begin{tabular}{|c|c|c|c|}
\hline \multirow{2}{*}{ No. } & $M_{b, a}$ & $\sigma_{a}$ & $N_{f}$ \\
\hline & $\mathrm{Nm}$ & $\mathrm{MPa}$ & - \\
\hline 1 & 12.5 & 123.58 & 276,742 \\
\hline 2 & 15.2 & 150.27 & 104,184 \\
\hline 3 & 15.7 & 155.22 & 883,96 \\
\hline 4 & 12.6 & 124.57 & 178,284 \\
\hline 5 & 11.1 & 109.74 & 328,443 \\
\hline 6 & 15.7 & 155.22 & 126,142 \\
\hline 7 & 12.6 & 124.57 & 263,049 \\
\hline 8 & 11.4 & 112.70 & 641,145 \\
\hline 9 & 11.4 & 112.70 & 446,843 \\
\hline 10 & 10.4 & 102.82 & 619,696 \\
\hline 11 & 10.4 & 102.82 & $1,100,137$ \\
\hline 12 & 11.5 & 113.69 & 283,144 \\
\hline 13 & 11.1 & 109.74 & 317,796 \\
\hline 14 & 11.3 & 111.72 & 284,989 \\
\hline 15 & 16.4 & 162.14 & 88,547 \\
\hline 16 & 10.9 & 107.76 & 410,442 \\
\hline 17 & 11.1 & 109.74 & 620,846 \\
\hline 18 & 16.5 & 163.12 & 144,449 \\
\hline
\end{tabular}

Table 6. Results of fatigue tests on samples after 7 days in a $3.5 \% \mathrm{NaCl}$ solution in demineralised water.

\begin{tabular}{cccc}
\hline \multirow{2}{*}{ No. } & $\boldsymbol{M}_{\boldsymbol{b}, \boldsymbol{a}}$ & $\sigma_{\boldsymbol{a}}$ & $\boldsymbol{N}_{\boldsymbol{f}}$ \\
\cline { 2 - 4 } & $\mathbf{N m}$ & $\mathbf{M P a}$ & - \\
\hline 1 & 22.7 & 224.42 & 53,198 \\
2 & 23.0 & 227.39 & 56,089 \\
3 & 23.0 & 228.37 & 56,387 \\
4 & 15.4 & 152.25 & 374,987 \\
5 & 15.7 & 155.22 & 217,172 \\
6 & 15.3 & 151.26 & 529,011 \\
7 & 15.3 & 151.26 & 850,634 \\
8 & 19.2 & 189.82 & 185,861 \\
9 & 18.9 & 186.85 & 136,600 \\
10 & 18.3 & 180.92 & 166,471 \\
11 & 16.0 & 158.18 & 191,783 \\
\hline
\end{tabular}


Table 7. Results of fatigue tests on samples after 14 days in a $3.5 \% \mathrm{NaCl}$ solution in demineralised water.

\begin{tabular}{cccc}
\hline \multirow{2}{*}{ No. } & $\boldsymbol{M}_{\boldsymbol{b}, \boldsymbol{a}}$ & $\sigma_{\boldsymbol{a}}$ & $\boldsymbol{N}_{\boldsymbol{f}}$ \\
\cline { 2 - 4 } & $\mathbf{N m}$ & $\mathbf{M P a}$ & - \\
\hline 1 & 14.0 & 138.41 & $1,486,798$ \\
2 & 13.8 & 136.43 & 610,621 \\
3 & 13.8 & 136.43 & 321,025 \\
4 & 14.1 & 139.40 & 199,693 \\
5 & 22.2 & 219.48 & 77,134 \\
6 & 22.4 & 221.45 & 52,587 \\
7 & 22.0 & 217.50 & 45,241 \\
8 & 18.7 & 184.87 & 99,541 \\
9 & 14.3 & 141.37 & 988,046 \\
\hline
\end{tabular}

Table 8. Results of fatigue tests of samples after 7 days in a $3.5 \% \mathrm{NaCl}$ solution in demineralised water.

\begin{tabular}{cccc}
\hline \multirow{2}{*}{ No. } & $\boldsymbol{M}_{\boldsymbol{b}, \boldsymbol{a}}$ & $\sigma_{\boldsymbol{a}}$ & $\boldsymbol{N}_{\boldsymbol{f}}$ \\
\cline { 2 - 4 } & $\mathbf{N m}$ & $\mathbf{M P a}$ & - \\
\hline 1 & 14.0 & 138.41 & $1,945,988$ \\
2 & 14.2 & 140.39 & 587,437 \\
3 & 12.3 & 121.60 & $1,839,387$ \\
4 & 22.0 & 217.50 & 66,984 \\
5 & 13.5 & 133.47 & 734,042 \\
6 & 12.8 & 126.55 & 768,036 \\
7 & 20.8 & 205.64 & 65,542 \\
8 & 20.7 & 204.65 & 80,335 \\
9 & 15.6 & 154.23 & 165,833 \\
\hline
\end{tabular}

Pictures of the fatigue fracture of the samples are shown in Figures 4 and 5. The clearly visible origin and the lack of front lines indicate uniform propagation of the fatigue crack. Microscopic images of crack origin showing the pit are shown in Figures 6 and 7.

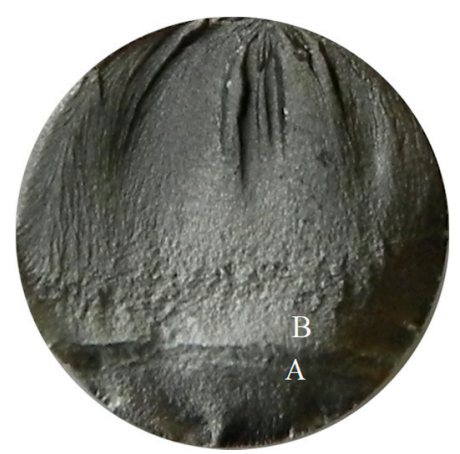

(a)

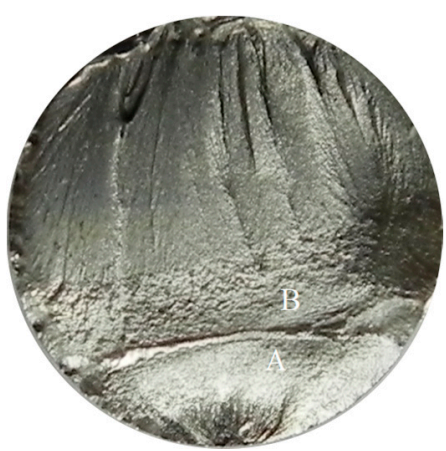

(b)

Figure 4. Fatigue fracture of exemplary samples from a series subjected to the solution in tap water, submitted to stress amplitude $\sigma_{a}=162 \mathrm{MPa}$ : (a) 7 days of immersion (Sample No. 3, Table 4); (b) 14 days of immersion (Sample No. 15, Table 5). Cracks originated from the bottom of the specimen, where: A - crack growth region, B-fast fracture zone. 


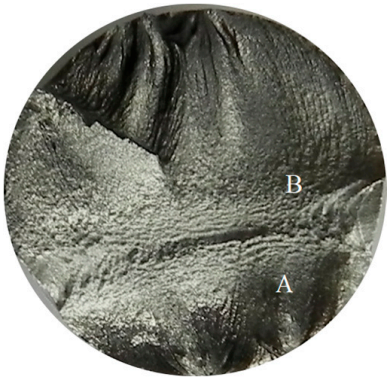

(a)

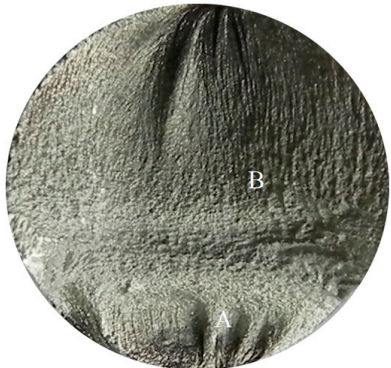

(b)

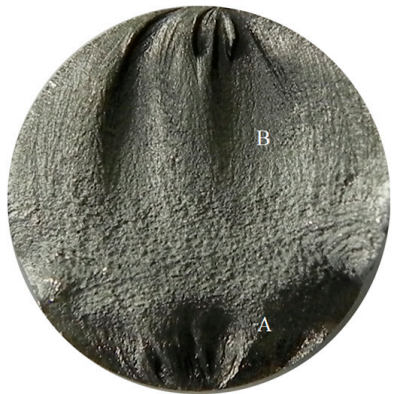

(c)

Figure 5. Fatigue fracture of an exemplary samples from a series subjected to the solution in demineralised water, submitted to stress amplitude $\sigma_{a}$ within a range from 217 to $227 \mathrm{MPa}$ : (a) 7 days of immersion (Sample No. 2, Table 6); (b) 14 days of immersion (Sample No. 6, Table 7); (c) 28 days of immersion (Sample No. 4, Table 8). Cracks originated at the surface, from the bottom of the specimen, where: A—crack growth region, B-fast fracture zone.

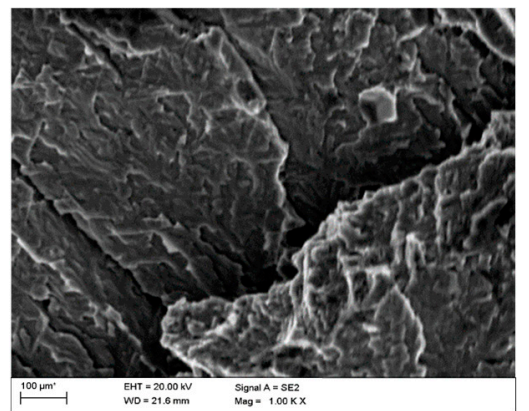

(a)

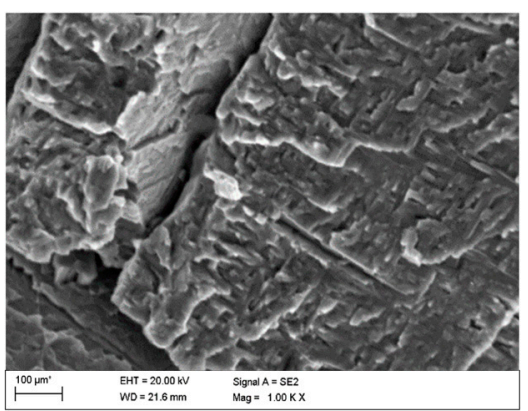

(b)

Figure 6. Microscopic images of crack origin, sample from a series subjected to the solution in tap water: (a) sample in Figure 4a, (b) sample in Figure 4b.

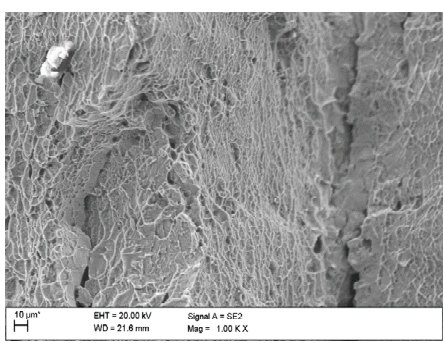

(a)

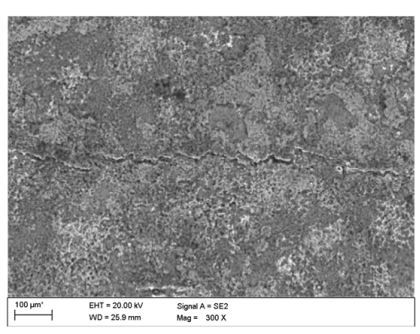

(b)

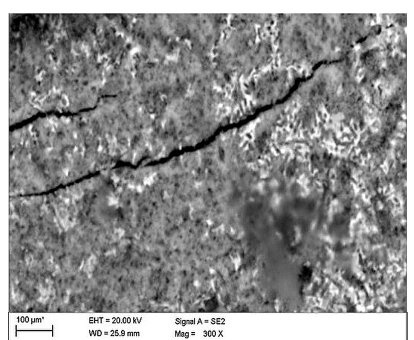

(c)

Figure 7. Microscopic images of crack origin, sample from a series subjected to the solution in tap water: (a) sample in Figure 5a, (b) sample in Figure 5b, (c) sample in Figure 5c.

Fractographic observation of the tested material, both for the first and second series of tests, shown a typical ductile fracture (Figures 8-14). Developed crack area was observed within the specimen axis. The pattern of cracking depends on the overall structural phenomena occurring during the strain of the material, but it is also important to take into account the chemical activity of the environment in which the material works, as corrosion promotes the nucleation and development of cracks in structural components.

Figures 8-11 show fracture images after 7 and 14 days of testing in tap water, respectively, where the zone of the ductile fracture of the tested alloy is visible.

Figures 12-14 shows fractographic fracture images after 7, 14 and 28 days of test conducted in demineralised water. 


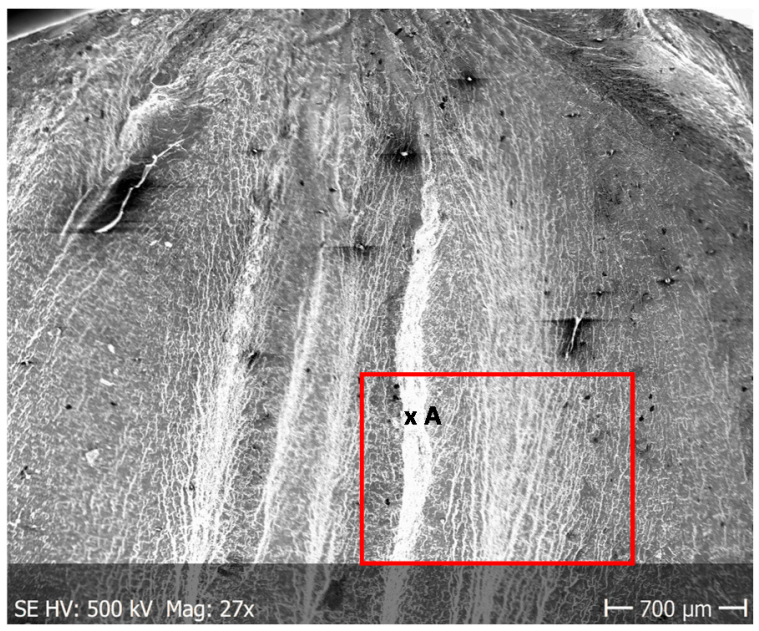

Figure 8. Fracture images after 7 days of testing in tap water (sample shown in Figure 4a).

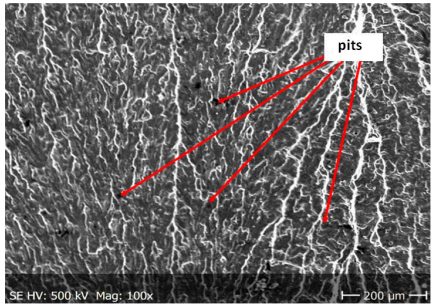

(a)

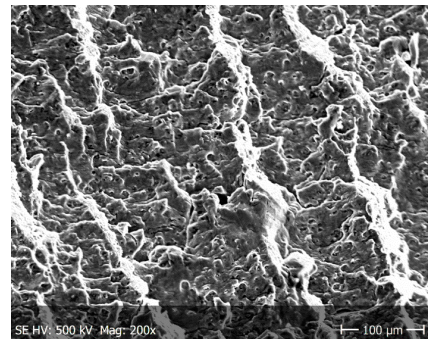

(b)

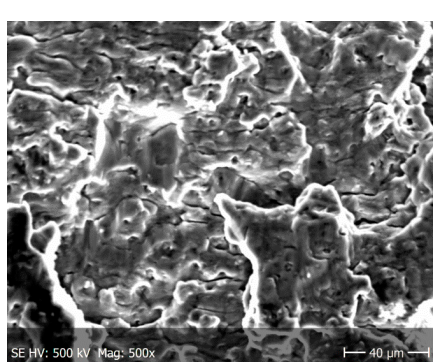

(c)

Figure 9. (a-c) Fracture images within area A (Figure 8).

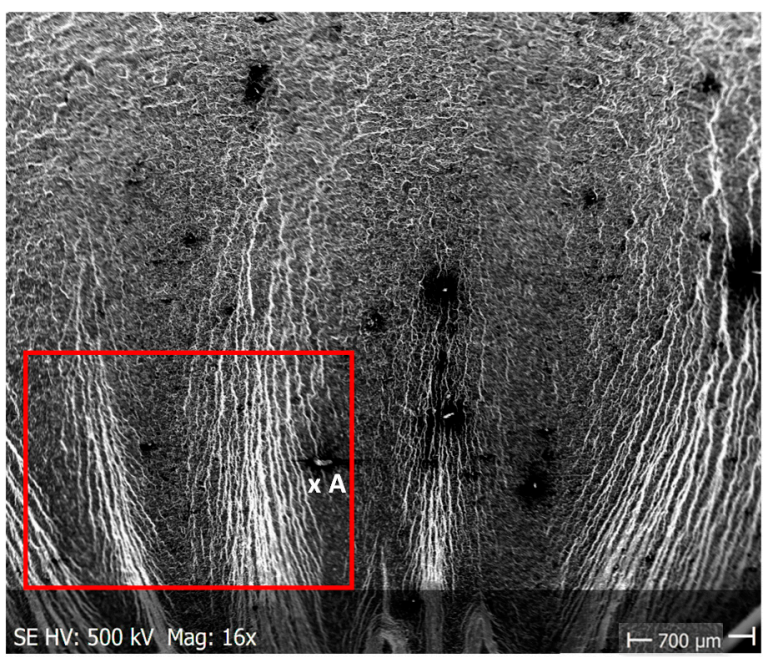

Figure 10. Fracture images after 14 days of testing in tap water (sample shown in Figure 4b).

The observations carried out with the scanning electron microscope (SEM) allowed to conclude that the tested alloy is subjected to local pitting corrosion as a result of the break of passive layer. This phenomenon occurred regardless of the immersion duration and corrosive environment. However, more pits were formed on the surface of the alloy being longer exposed to the corrosive environment (Figures 15 and 16). 


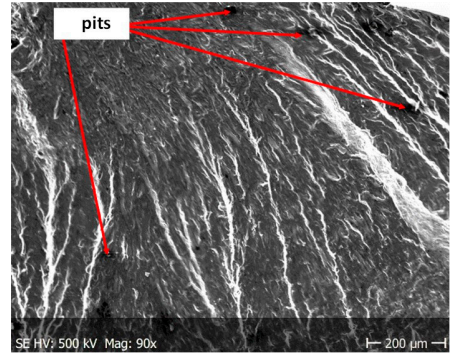

(a)

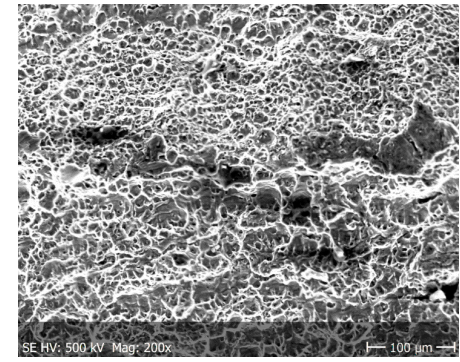

(b)

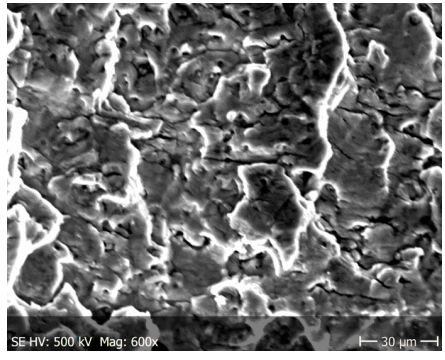

(c)

Figure 11. (a-c) Fracture images within area A (Figure 10).

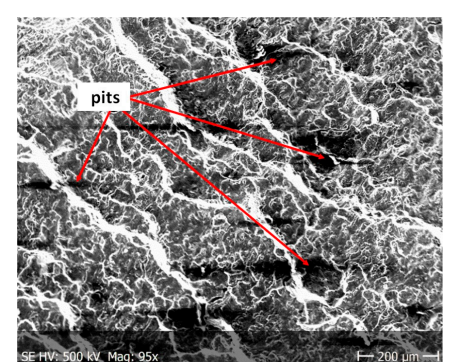

(a)

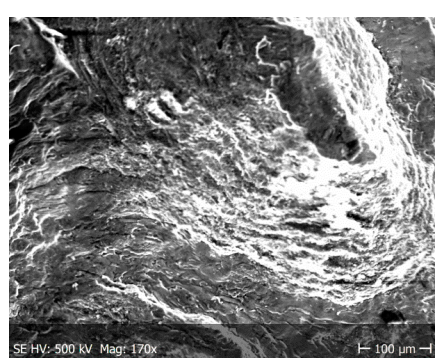

(b)

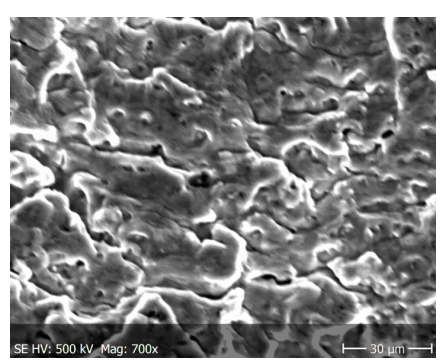

(c)

Figure 12. $(\mathbf{a}-\mathbf{c})$ Fracture images after 7 days in demineralised water (images taken at fracture surface of sample shown in Figure 5a).

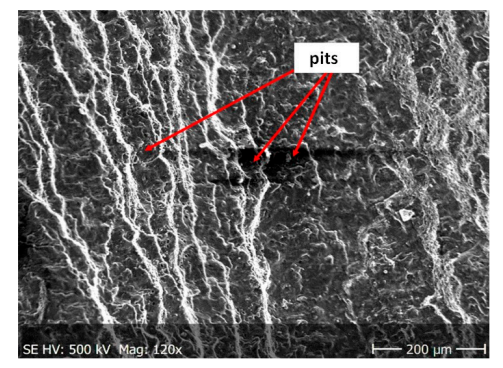

(a)

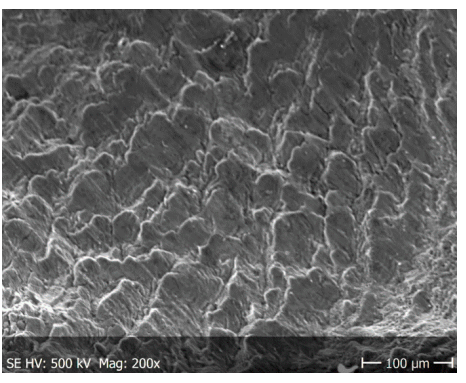

(b)

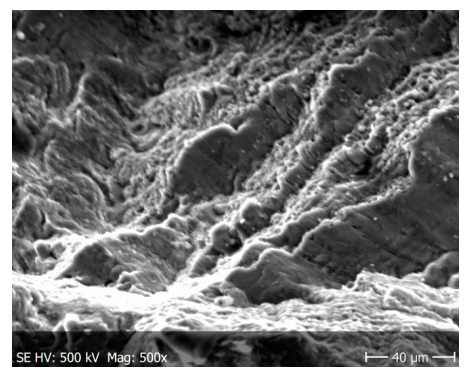

(c)

Figure 13. $(\mathbf{a}-\mathbf{c})$ Fracture images after 14 days in demineralised water (images taken at fracture surface of sample shown in Figure 5b).

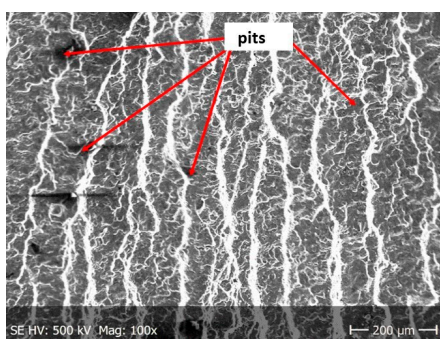

(a)

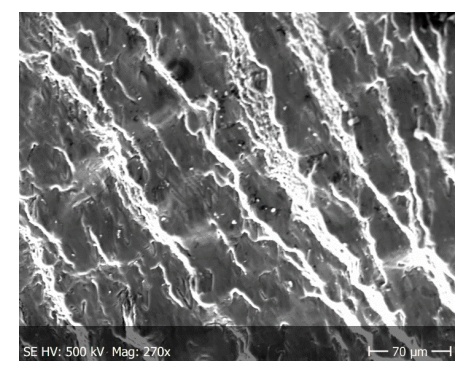

(b)

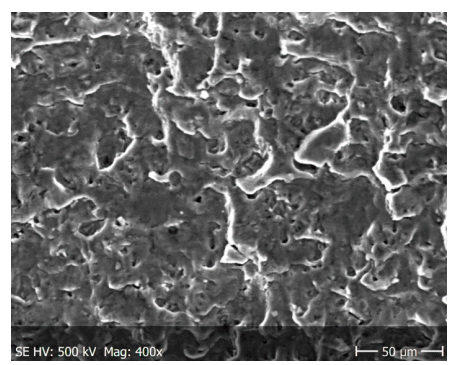

(c)

Figure 14. $(\mathbf{a}-\mathbf{c})$ Fracture images after 28 days in demineralised water (images taken at fracture surface of sample shown in Figure 5c). 


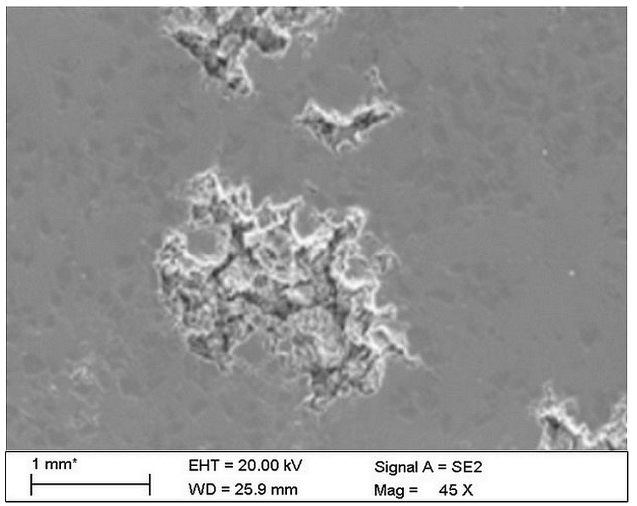

(a)

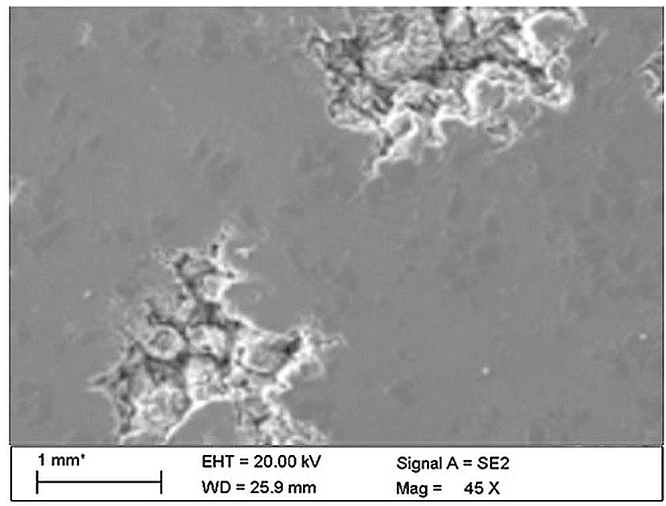

(b)

Figure 15. Surface of tested aluminium alloy after 7 (a) and 14 (b) days of testing in tap water. Visible changes in form of pits.

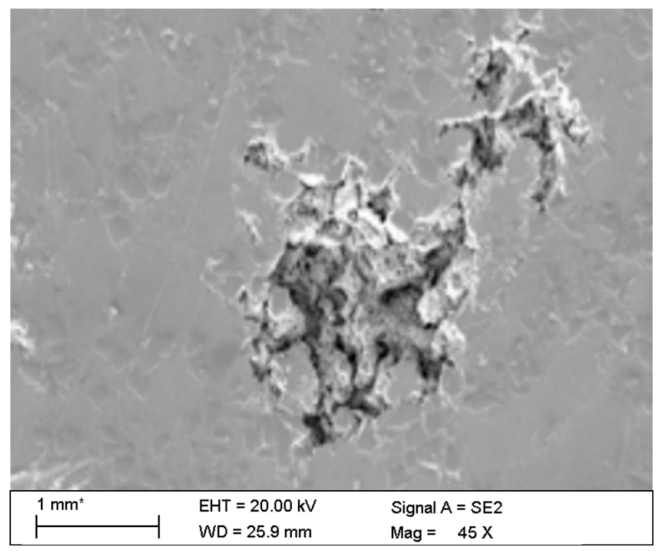

(a)

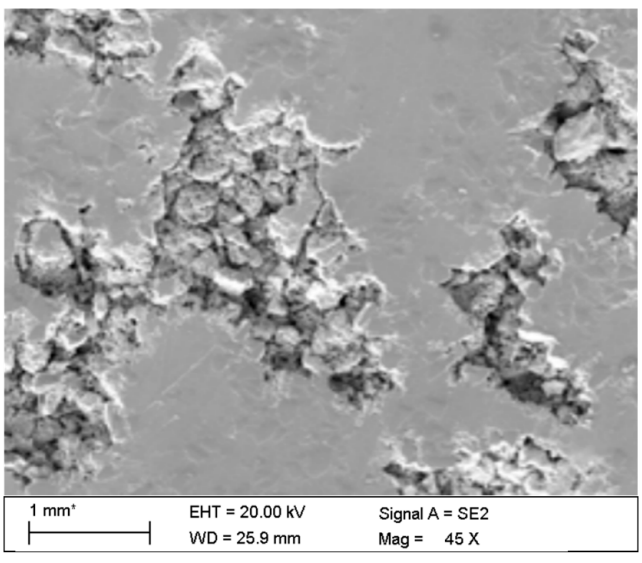

(b)

Figure 16. Surface of tested aluminium alloy after 7 (a) and 14 (b) days in demineralised water. Visible changes in form of pits.

This phenomenon indicates a significant influence of chloride ion concentration in the corrosive medium on the formation of pits. Although pits are formed evenly over the entire exposed area of the sample during both tests: in tap and demineralised water, the damage increases along with the immersion duration. Figure 17 show pictures of the interior of pits created during corrosion tests. They indicate that the surface is significantly etched. The pitting starts on the surface of the material, but also quickly progresses inwards. Very often the rest of the metal on the surface remains intact. Such a phenomenon usually occurs in materials that are subject to self-passivation, such as stainless steel or aluminium alloys. Usually, pits are first nucleated on the metal surface and then develop and propagate inwards, hence the visible pits at material fractures. Pit nucleation occurs at the weakest points of the passive layer: in places of mechanical damage, near some non-metallic inclusions or at grain boundaries. Probably, the nucleation is preceded by adsorption of aggressive ions, especially $\mathrm{Cl}$, on the surface. Then the ions penetrate the passive layer by migration or penetration.

The observed fatigue strength allowed to formulate the S-N fatigue characteristics in a double logarithmic system (according to ASTM [31]):

$$
\log N_{f}=B-m \log \sigma_{a},
$$

where $N_{f}=$ durability, the number of cycles to failure, -; $B=$ material parameter, $-; m=$ slope, - ; $\sigma_{a}=$ elastic stress amplitude, $\mathrm{MPa}$. 


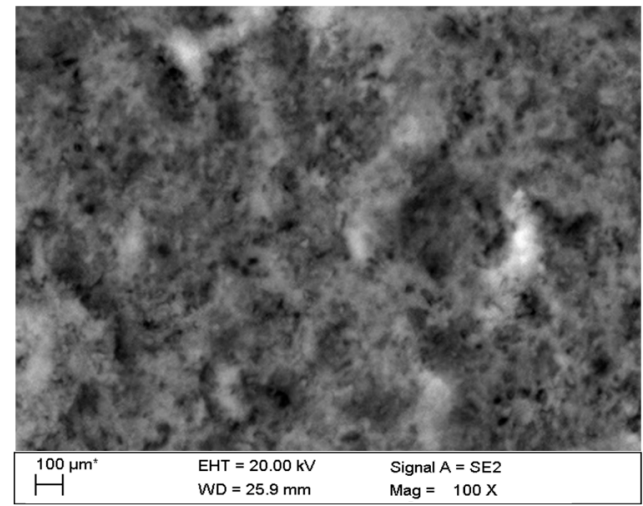

(a)

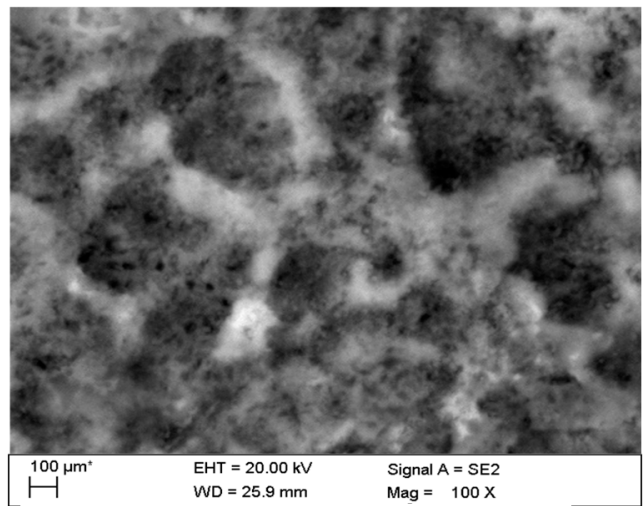

(b)

Figure 17. Interior of pits created during corrosion tests: (a) in tap water, (b) in demineralised water.

Fatigue characteristics were developed separately for each variant and test series. In order to determine the values of parameters $B$ and $m$ in Equation (2), a linear regression model was used. The quality of approximation was assessed by means of correlation coefficient $\rho$. The values obtained are shown in Table 9. The processed data required to reproduce these findings can be found at [32].

Table 9. Fitting parameters.

\begin{tabular}{ccccc}
\hline Solvent & Pre-Corrosion Time & $\mathbf{B},-$ & $\mathbf{m}, \mathbf{-}$ & $\rho_{\mathbf{r}} \mathbf{-}$ \\
\hline \multirow{2}{*}{ Tap water } & 7 days & 12.06 & 3.04 & -0.88 \\
& 14 days & 13.88 & 4.03 & -0.90 \\
\hline \multirow{2}{*}{ Demineralised water } & 7 days & 16.42 & 4.95 & -0.92 \\
& 14 days & 16.47 & 5.01 & -0.88 \\
& 28 days & 17.96 & 5.66 & -0.93 \\
\hline
\end{tabular}

The obtained results were compared to the results of the tests of samples in their nominal state, i.e., not subjected by a corrosive environment, described, among others, in [33-35]. The formulated characteristics were compared with the nominal characteristics determined by Kurek et al. [33], with Equation (2) parameters $B=21.71$ and $m=7.03$. The comparison of fatigue characteristics of both test series (Tables 4-8) with nominal characteristics is shown in Figures 18 and 19, respectively.

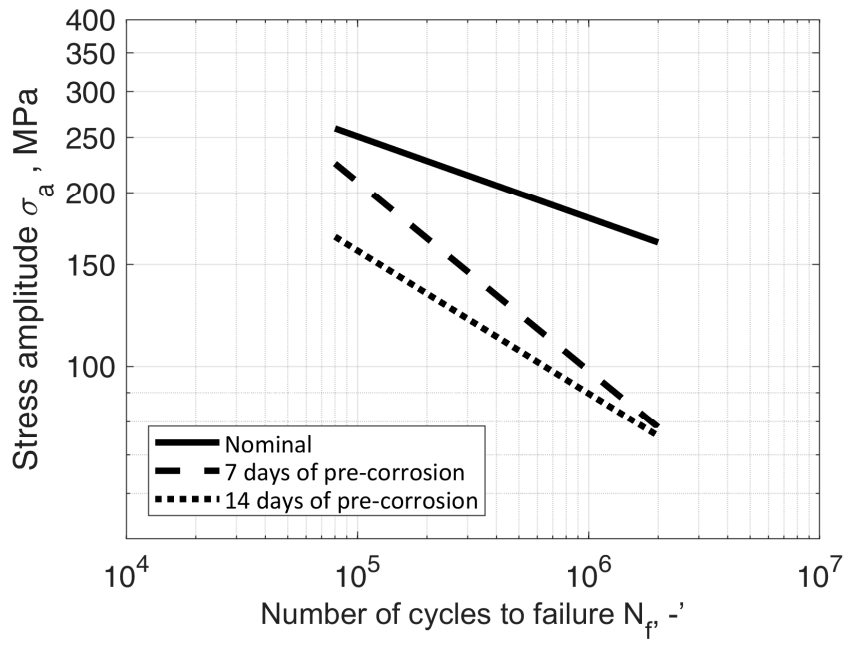

Figure 18. S-N data of AW-2017A-T4 material in nominal condition (room temperature, in air) and samples immersed in tap water solution for 7 and 14 days prior to bending fatigue tests. 


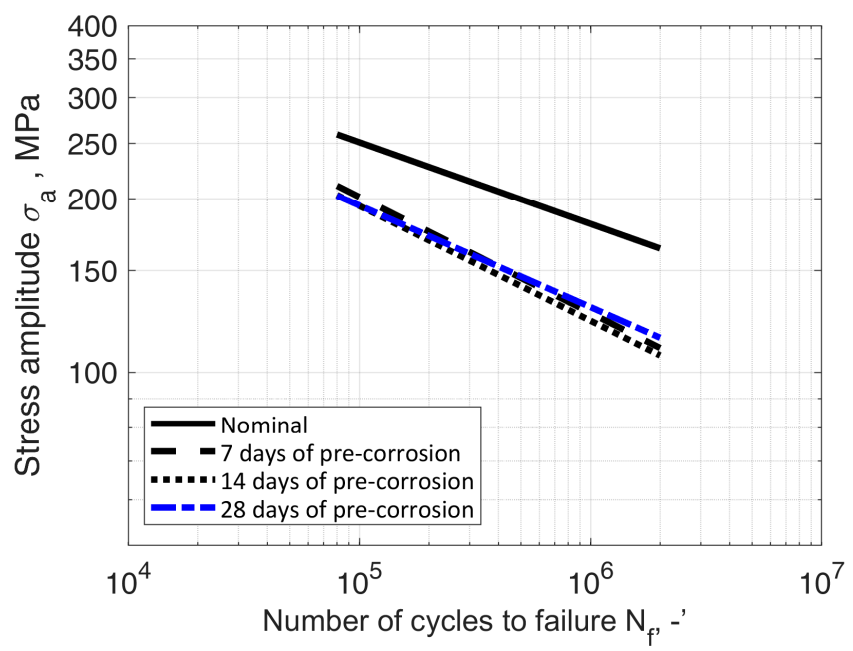

Figure 19. S-N data of AW-2017A-T4 material in nominal condition (room temperature, in air) and samples immersed in demineralised water solution for 7, 14 and 28 days prior to bending fatigue tests.

\section{Discussion}

The paper described two series of fatigue tests of samples made of aluminium alloy AW-2017A under cyclic bending load, exposed to electrochemical corrosion caused by immersion in an electrolyte, a $3.5 \mathrm{wt} \%$ solution of $\mathrm{NaCl}$ in water. The first series of tests concerned a solution in tap water, and the second series concerned a solution in demineralised water. In each series, fatigue fractures indicated uniform crack propagation. The obtained test results feature Pearson correlation coefficient values between -0.88 and -0.90 in case of tap water solution and between -0.88 and -0.93 in case of demineralised water solution. The comparison showed a decrease in fatigue strength in each case except the 28 days of pre-corrosion serie. In this case it was slightly higher than the 7 and 14 days series, but it has to be mentioned that for this solution all S-N curves are very close to each other.

The microscopic observations show that all samples of the tested alloy have undergone pitting corrosion. The smallest number of pits was formed on the sample after the shortest immersion duration ( 7 days, Figures 15a and 16a), more pits were visible on the samples immersed for 14 days (Figures 15b and 16b), which is consistent with the results obtained from fatigue tests. The observations indicate a disruption of the anode layer and the occurrence of micro cracks which transform into corrosion. In addition, it is not possible to create a passive layer on the surface of the material and for this reason it is easier to initiate pitting on its surface. Larger corrosion damage probably results from the extension of the time of exposure to aggressive corrosive environment, which simultaneously translates into shorter fatigue life of the material. The results have shown that after a longer period of exposure to $\mathrm{NaCl}$ solution pits are formed on the surface of the samples with higher density.

From the additional observations it can be seen that the propagation of a crack was accompanied by intense plastic strain and accumulation of deformation strain energy in the material. Plastic deformation of the material was initiated in the surface layer in grains with the crystallographic orientation in the easy glide direction and near the stress concentrators (i.e., in weakened parts of the material). The process of ductile cracking is associated with high plastic strain, so it requires a significant energy expenditure for crack propagation. The topography of the developed crack area consists of a large collection of pits (craters) of various sizes and shapes, which can be viewed in Figure 9a, Figure 11a, Figure 12a, Figures 13a and 14a. Corrosion pits were observed also at the crack origin. In the case of tests carried out in tap water and in demineralised water it was observed that with increasing exposure time to the corrosion environment, the corrosive pits became more widespread (Figure 9a, Figure 11a, Figure 12a, Figures 13a and 14a), which caused geometric irregularities in the material. Such a phenomenon leads to local plastic deformation of the material. It points on plastic 
fatigue cracking, which is indicated by the ductile fractures of the analysed samples (Figure 9b,c, Figure 11b,c, Figure 12b,c, Figure 13b,c and Figure 14b,c).

In the case of the first series of tests, a clear influence of the immersion duration can be observed. This can be explained through the fact that with the increase of corrosion pits fatigue crack initiation life becomes shorter, although this trend decreases in the high cycle fatigue region. These results can be interpreted as evidence of the importance of the joint effect of stress and corrosion processes on high cycle fatigue behaviour. Globally, the results showed a decrease in the conventional fatigue limit (i.e., stress at $1 \times 10^{7}$ cycles) and a slight change in the slope of the S-N diagram, which translates into a higher susceptibility to failure and a decrease in the influence of bending stress on fatigue life, with an increase in the time of corrosive processes. The above observation indicates a lesser influence of material properties on its fatigue strength at low stress values and high number of cycles. In this region curves for both immersion durations are very close to each other and the obtained life would be close for both of them.

The reason for the differences in fatigue life can be attributed to the presence of plastic strain, which considerably influences fatigue processes in aluminium alloys [36,37], as was also shown in fractographic tests. Yang et al., through fatigue tests of different alloys, have proved that plastic properties strongly influence fatigue lives [36]. At higher stress amplitudes, the presence of corrosion pits lead to local plastic strain and the coalescence of flaws. The higher the amplitudes, the deeper the cavity is. The topography of the obtained fracture planes exhibited differences between samples of different immersion times. From the analysis of the two fracture planes in Figure 4, it can be seen that the crack originated always at the surface and that the rapid fracture region has slightly decreased with the elongation of immersion time. The fractography evidenced the typical ductile behavior of the fatigue fracture with the increased rate of plastic strains in the case of the samples with longer immersion times. This further indicates the existence of local stress concentrations of a greater magnitude than in the case of shorter immersion times. This can be attributed to the notch effect of a geometrical origin, such as pitting. The pitting mechanism promotes intergranular corrosion attack, which can result in geometrical discontinuities. Corrosion pits initiated the formation of channels linking the corroded surface and uncorroded material interior, which caused discontinuities and the expansion of corrosion processes.

In the high cycle fatigue, the results are most likely affected by the notch effect of material origin. Due to the ongoing electrochemical reactions, corrosion processes are also responsible for the production of hydrogen on the material surface. The production of hydrogen can evolve and develop from the surface into the interior of the material, along with the crack tip. Such behaviour causes local embrittlement, responsible for variation in local fracture toughness $[38,39]$. This is typical at low strain rates [39].

In the case of the second series of tests, where demineralised water was the solvent, the observed decrease was almost independent of the length of immersion time. This observation was confirmed during additional tests consisting of 28 days' immersion in solution. The difference in durability between the samples from both series is most likely caused by different corrosion dynamics, due to the properties of such an electrolyte, determined by low solvent conductivity.

\section{Conclusions}

The paper describes bending fatigue tests of samples pre-corroded in a 3.5\% wt. solution of $\mathrm{NaCl}$ in tap and demineralised water. From the results, the following conclusions can be drawn:

(1) The results from both series of tests showed a decrease in fatigue life due to the susceptibility of the tested material to pitting corrosion processes and the plastic strain mechanisms;

(2) The results of tests of samples from the series immersed in the solution in tap water showed a decrease in stress at $1 \times 10^{7}$ cycles (i.e., the conventional fatigue limit), nearly the same in case of 7 and 14 days of immersion duration, although a slope different between both S-N diagrams 
can be observed. Different slopes which translates into a higher susceptibility to failure and a decrease in the influence of bending stress on fatigue life with an increase in pre-corrosion time;

(3) In the case of the samples from the series immersed in the solution in demineralised water, only a slight impact of the length of time spent in the corrosive medium on fatigue life was observed. The observation on samples after 7 and 14 days in solution was confirmed by the results of additional fatigue tests, on samples after 28 days in solution. The difference in durability between the samples from both series is most probably caused by different corrosion dynamics resulting from the properties of such an electrolyte, determined by low solvent conductivity;

(4) fatigue fractures indicate uniform crack propagation;

(5) the obtained test results feature Pearson correlation coefficient value not less than -0.88 .

Author Contributions: Conceptualization: Ł.B. and T.Ł.; formal analysis: T.Ł. and J.M.; investigation, software, visualization Ł.B., and writing: Ł.B. and J.M. All authors have read and agreed to the published version of the manuscript.

Funding: This research received no external funding.

Conflicts of Interest: The authors declare that there is no conflict of interest.

\section{List of Symbols}

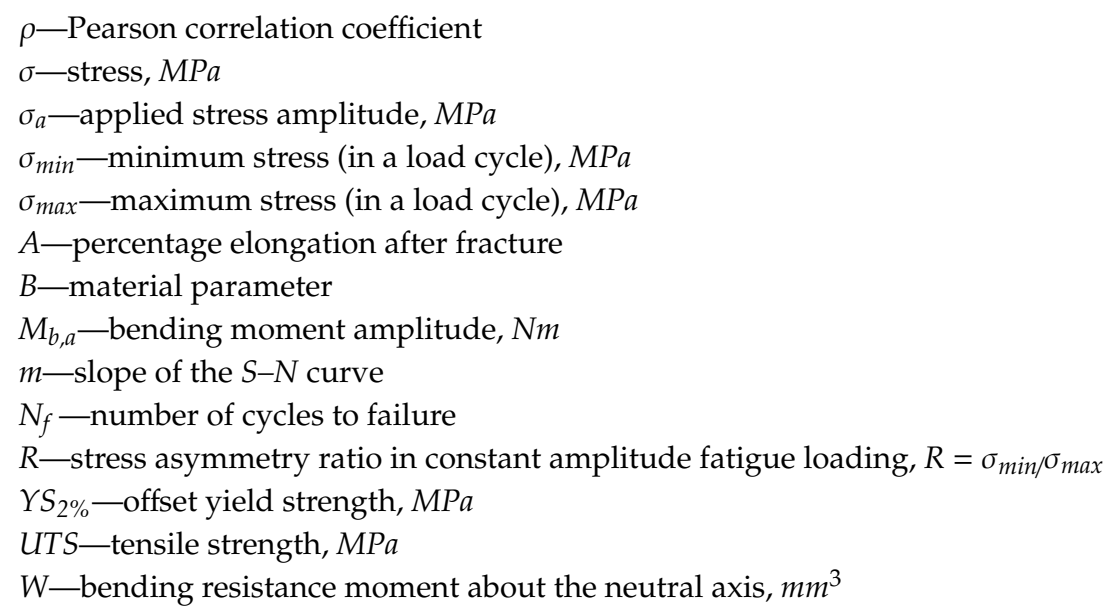

\section{References}

1. Dey, P.; Narasimhan, S.; Walbridge, S. Evaluation of Design Guidelines for the Serviceability Assessment of Aluminum Pedestrian Bridges. J. Bridge Eng. 2017, 22, 04016109. [CrossRef]

2. Zhu, P.; Ai, P.; Zhou, Y.; Xu, L.; Fan, H. Structural analyses of extruded CFRP tendon-anchor system and applications in thin-walled aluminum/CFRP bridge. Thin Walled Struct. 2018, 127, 556-573. [CrossRef]

3. Feng, R.; Liu, J. Numerical investigation and design of perforated aluminium alloy SHS and RHS columns. Eng. Struct. 2019, 199, 109591. [CrossRef]

4. Liu, H.; Chen, Z.; Han, Q.; Chen, B.; Bu, Y. Study on the thermal behavior of aluminum reticulated shell structures considering solar radiation. Thin Walled Struct. 2014, 85, 15-24. [CrossRef]

5. Li, Z.; Feng, R.; Wang, Y.; Wang, L. Experimental study on the effect of dents induced by impact on the fatigue life of 2024-T3 aluminum alloy plate. Eng. Struct. 2017, 137, 236-244. [CrossRef]

6. Arowosola, A.; Gaustad, G. Estimating increasing diversity and dissipative loss of critical metals in the aluminum automotive sector. Resour. Conserv. Recycl. 2019, 150, 104382. [CrossRef]

7. Poznak, A.; Freiberg, D.; Sanders, P. Chapter 10-Automotive wrought aluminum alloys. In Fundamentals of Aluminum Metallurgy; Lumley, R.N., Ed.; Woodhead Publishing Series in Metals and Surface Engineering; Woodhead Publishing: Cambridge, UK, 2018; pp. 333-386. [CrossRef]

8. Holmen, J.K.; Børvik, T.; Hopperstad, O.S. Experiments and simulations of empty and sand-filled aluminum alloy panels subjected to ballistic impact. Eng. Struct. 2017, 130, 216-228. [CrossRef] 
9. Aliha, M.R.M.; Kalantari, M.H.; Ghoreishi, S.M.N.; Torabi, A.R.; Etesam, S. Mixed mode I/II crack growth investigation for bi-metal FSW aluminum alloy AA7075-T6/pure copper joints. Theor. Appl. Fract. Mech. 2019, 103, 102243. [CrossRef]

10. Patel, A.R.; Kotadiya, D.J.; Kapopara, J.M.; Dalwadi, C.G.; Patel, N.P.; Rana, H.G. Investigation of Mechanical Properties for Hybrid Joint of Aluminum to Polymer using Friction Stir Welding (FSW). Mater. Today Proc. 2018, 5, 4242-4249. [CrossRef]

11. Xu, W.; Wang, H.; Luo, Y.; Li, W.; Fu, M.W. Mechanical behavior of 7085-T7452 aluminum alloy thick plate joint produced by double-sided friction stir welding: Effect of welding parameters and strain rates. J. Manuf. Process. 2018, 35, 261-270. [CrossRef]

12. Rambabu, P.; Eswara Prasad, N.; Kutumbarao, V.V.; Wanhill, R.J.H. Aluminum alloys for aerospace applications. In Aerospace Materials and Material Technologies: Volume 1: Aerospace Materials; Indian Institute of Metals Series; Springer: Singapore, 2017; pp. 29-52. [CrossRef]

13. Hernandez, F.C.R.; Ramírez, J.M.H.; Mackay, R. Al-Si Alloys: Automotive, Aeronautical, and Aerospace Applications; Springer International Publishing: Cham, Switzerland, 2017. [CrossRef]

14. Ruiz, J.; Elices, M. The role of environmental exposure in the fatigue behaviour of an aluminum alloy. Corros. Sci. 1997, 39, 2117-2141. [CrossRef]

15. Hall, M.M. Effect of cyclic crack opening displacement rate on corrosion fatigue crack velocity and fracture mode transitions for Al-Zn-Mg-Cu alloys. Corros. Sci. 2014, 81, 132-143. [CrossRef]

16. Kovalov, D.; Fekete, B.; Engelhardt, G.R.; Macdonald, D.D. Prediction of corrosion fatigue crack growth rate in alloys. Part II: Effect of electrochemical potential, $\mathrm{NaCl}$ concentration, and temperature on crack propagation in AA2024-T351. Corros. Sci. 2019, 152, 130-139. [CrossRef]

17. Dafang, W.; Yuewu, W.; Bing, P.; Meng, M.; Lin, Z. Experimental research on the ultimate strength of hard aluminum alloy 2017 subjected to short-time radioactive heating. Mater. Des. 2012, 40, 502-509. [CrossRef]

18. Moreto, J.A.; Gambonf, O.; Rucherf, C.O.F.T.; Romagnoli, F.; Moreira, M.F.; Beneduce, F.; Filho, W.W.B. Corrosion and fatigue behavior of new Al alloys. Procedia Eng. 2011, 10, 1521-1526. [CrossRef]

19. Ishihara, S.; Nan, Z.Y.; McEvily, A.J.; Goshima, T.; Sunada, S. On the initiation and growth behavior of corrosion pits during corrosion fatigue process of industrial pure aluminum. Int. J. Fatigue 2008, 30, 1659-1668. [CrossRef]

20. Stannard, T.J.; Williams, J.J.; Singh, S.S.; Sundaram Singaravelu, A.S.; Xiao, X.; Chawla, N. 3D time-resolved observations of corrosion and corrosion-fatigue crack initiation and growth in peak-aged Al 7075 using synchrotron X-ray tomography. Corros. Sci. 2018, 138, 340-352. [CrossRef]

21. Mishra, R.K. Study the effect of pre-corrosion on mechanical properties and fatigue life of aluminum alloy 8011. Mater. Today Proc. 2019, 25, 602-609. [CrossRef]

22. Baragetti, S.; Gerosa, R.; Villa, F. Step loading corrosion fatigue testing of 7075-T6 WC/C coated samples in air and methanol. Eng. Fract. Mech. 2016, 164, 106-116. [CrossRef]

23. Chanyathunyaroj, K.; Phetchcrai, S.; Laungsopapun, G.; Rengsomboon, A. Fatigue characteristics of 6061 aluminum alloy subject to $3.5 \% \mathrm{NaCl}$ environment. Int. J. Fatigue 2020, 133, 105420. [CrossRef]

24. Benedetti, M.; Fontanari, V.; Bandini, M. A simplified and fast method to predict plain and notch fatigue of shot peened high-strength aluminium alloys under reverse bending. Surf. Coat. Technol. 2014, 243, 2-9. [CrossRef]

25. Zhao, Y.; Zhai, X. Bending strength and design methods of the 6082-T6 aluminum alloy beams with circular hollow sections. Structures 2020, 26, 870-887. [CrossRef]

26. Khalid, Y.A.; Mutasher, S.A.; Sahari, B.B.; Hamouda, A.M.S. Bending fatigue behavior of hybrid aluminum/composite drive shafts. Mater. Des. 2007, 28, 329-334. [CrossRef]

27. Williams, J.C.; Starke, E.A. Progress in structural materials for aerospace systems11The Golden Jubilee Issue-Selected topics in Materials Science and Engineering: Past, Present and Future, edited by S. Suresh. Acta Mater. 2003, 51, 5775-5799. [CrossRef]

28. Ahmad, Z. Chapter 10-Atmospheric corrosion. In Principles of Corrosion Engineering and Corrosion Control; Ahmad, Z., Ed.; Butterworth-Heinemann: Oxford, UK, 2006; pp. 550-575. [CrossRef]

29. Lacková, P.; Hagarová, M.; Cervová, J.; Mamuzić, I. Corrosion Properties of Selected Aluminum Alloys in Model Electrolytes. Acta Metall. Slovaca 2014, 20, 209-216. [CrossRef]

30. Achtelik, H.; Kurek, M.; Kurek, A.; Kluger, K.; Pawliczek, R.; Łagoda, T. Non-standard fatigue stands for material testing under bending and torsion loadings. AIP Conf. Proc. 2018, 2029, 020001. [CrossRef] 
31. E08 Committee. Practice for Statistical Analysis of Linear or Linearized Stress-Life (S-N) and Strain-Life (-N) Fatigue Data; ASTM International: West Conshohocken, PA, USA, 2004.

32. Blacha, L. Data for: Fatigue Life of Aluminium Alloy 2017-T4 In Bending Conditions After Preliminary Corrosion Period. Mendeley Data 2020. [CrossRef]

33. Kurek, A.; Koziarska, J.; Kluger, K.; Łagoda, T. Fatigue life of 2017A-T4 aluminum alloy under different types of stress. J. Mach. Constr. Maint. Probl. Eksploat. 2017, 4, 53-61.

34. Kardas, D.; Kluger, K.; Łagoda, T.; Ogonowski, P. Fatigue life of 2017(A) aluminum alloy under proportional constant-amplitude bending with torsion in the energy approach. Mater. Sci. 2008, 44, 541-549. [CrossRef]

35. Niesłony, A.; Łagoda, T.; Walat, K.; Kurek, M. Multiaxial fatigue behaviour of AA6068 and AA2017A aluminum alloys under in-phase bending with torsion loading condition. Mater. Und Werkst. 2014, 45, 947-952. [CrossRef]

36. Yang, H.; Wang, Y.; Wang, X.; Pan, P.; Jia, D. The Effects of Corrosive Media on Fatigue Performance of Structural Aluminum Alloys. Metals 2016, 6, 160. [CrossRef]

37. Chen, Y.; Liu, C.; Zhou, J.; Wang, X. Multiaxial fatigue behaviors of 2024-T4 aluminum alloy under different corrosion conditions. Int. J. Fatigue 2017, 98, 269-278. [CrossRef]

38. Benavides, S. Corrosion Control in the Aerospace Industry; Elsevier: Amsterdam, The Netherlands, 2009; ISBN 978-1-84569-553-8.

39. Ricker, R.E.; Duquette, D. Corrosion fatigue of aluminum alloys. In Proceedings of the First Joint DoD/FAA/ NASA Conference on Aging Aircraft, Odgen, UT, USA, 8-10 July 1997; pp. 465-473.

(C) 2020 by the authors. Licensee MDPI, Basel, Switzerland. This article is an open access article distributed under the terms and conditions of the Creative Commons Attribution (CC BY) license (http://creativecommons.org/licenses/by/4.0/). 